\title{
A relevância do uso de técnicas qualitativas em pesquisas sobre a biomedicina*
}

\author{
The relevance of qualitative techniques in biomedical research
}

Kenneth Rochel de Camargo Jr. ${ }^{1}$

\footnotetext{
* Texto baseado na apresentação da mesa redonda"Pesquisa Qualitativa em Saúde", no IV Fórum de Investigação Qualitativa ellI Painel Brasileiro-Alemão de Pesquisa, realizado em Juiz deFora, agosto de 2005

${ }^{1}$ Departamento de Planejamento e Administração em Saúde, Instituto de M edicina Social, UERJ. Rua São Francisco Xavier 524/70 andar/Bloco D, M aracanã. 20559-900 Rio de Janeiro RJ. kenneth@uerj.br
}

Abstract On observing how qualitative and quantitative studies are reported in the biomedical literature it becomes evident that, besides the virtual absence of the former, they are presented in different ways. Authors of qualitative studies seem to need almost invariably to explain why they choose a qualitative approach whereas that does not occur in quantitative studies. This paper takes Ludwik Fleck's comparative epistemology as a means of exploring those differences empirically, illustrating on the basis of two studies dealing with different aspects of biomedical practices how qualitative methods can elucidate a variety of questions pertaining to this field. The paper concludes presenting some structural characteristics of the biomedical field which on one hand, would not be explored properly without employing qualitative methods and, on the other hand, can help understanding the little valuegiven to qualitative techniques in this area.

Key words Biomedicine, Epistemology, Social sciences in health
Resumo Ao observar-se a forma como estudos qualitativos e quantitativos são relatados na literatura biomédica, vê-se que, além da virtual ausência dos primeiros, há uma forma diferenciada na sua apresentação. 0 s autores de estudos qualitativos parecem necessitar quase que invariavelmente de explicar a necessidade de sua opção pelo qualitativo, o quenão ocorre com os estudos quantitativos. Estetexto seapóia na epistemologia comparativa de Ludwik Fleck como forma de explorar essas diferenças empiricamente, ilustrando, com base em dois estudos que abordam diferentes aspectos das práticas no campo biomédico, como a investigação com baseem técnicas qualitativas pode iluminar diferentes questões desse campo. 0 artigo conclui com a exposição de algumas características estruturais do campo biomédico que, por um lado, não seriam bem exploradas a não ser pelo emprego das técnicas qualitativas utilizadas nos respectivos estudos, e que, por outro lado, ajudam a entender o menor valor atribuído às mesmas no interior do próprio campo. Palavras-chave Biomedicina, Epistemologia, Ciências sociais em saúde 
Charles Taylor ${ }^{1}$, ao discutir o papel fundamental do círculo hermenêutico para as ciências do homem, contrasta o modo de produção de conhecimento destas, necessariamente qualitativo por conta desta característica, com uma concepção de ciência (atécerto ponto datada) como a aplicação de técnicas quantitativas a dados brutos. Como estemodelo édifusamentepercebido como a "verdadeira ciência", segue-se uma assimetria fundamental na apresentação de pesquisas empíricas, onde com freqüência os autores sentem-se compelidos a justificar sua escolha metodológica, ao contrário dos que adotam técnicas quantitativas.

Similarmente, num livro deintrodução àme todologia qualitativa, $M$ aykrut e $M$ orehouse ${ }^{2}$ fazem a observação de que, ao contrário dos mé todos quantitativos, com freqüência demandasedos primeiros justificativas filosóficas para seu emprego. Segundo estes autores, isto se deve à incompreensão dos princípios filosóficos subjacentes à investigação qualitativa; esta explicação é parcial, como comentarei mais adiante, mas o que desejo assinalar é uma certa percepção de "inferioridade epistemológica" que leva às situações descritas tanto por Taylor quanto pelos dois últimos autores.

A área de saúde, de um modo geral, confirma esta regra; basta contemplar qualquer periódico médico para ver-se a predominância quase absoluta de artigos com base em métodos quantitativos, em especial as técnicas estatísticas. M ais ainda, ao longo do tempo, esta éuma tendência crescente, reduzindo-se cada vez mais o espaço para textos baseados em técnicas qualitativas. Apenas a título de ilustração, uma busca na base de dados Ovid em três das mais importantes revistas médicas - N ew England J ournal of M edicine, Lancet eBritish M edical J ournal - pelo unitermo "qualitative research" no triênio 2004 a 2006 não identificou nenhum artigo nas duas primeiras, e apenas um na última. Outro unitermo, "focus group", não identificou no mesmo período nenhum artigo na primeira, três na segunda e sete na última. 0 total de artigos publicados pelas revistas no período citado foi, também respectivamente, $4.433,5.183$ e 7.099. Com todas as limitaçõesine rentes à busca por unitermos em bases bibliográficas, trata-se de forte evidência da predominância da lógica quantitativa na publicação.

Esta ampla hegemonia obscurece um aspecto fundamental, contudo: a de que a base de onde surgiu o moderno conhecimento na área de saúde (em particular da medicina), a clínica, é uma técnica essencialmente qualitativa. A medicina moderna nasce, segundo Foucault ${ }^{3}$, a partir do surgimento de uma disciplina eminentemente qualitativa, a anátomo-clínica, e um de seus atributos certamente éo que Ginzburg ${ }^{4}$ define como paradigma indiciário, isto é, um modo de produção deconhecimentosqueseconcretiza na individualização de singularidades a partir de indícios recolhidos de forma não-sistemática. Isto se reflete na forma como médicos hierarquizam e selecionam diferentes estratégias de validação e incorporação de novos conhecimentos, levando-os a adotar uma estratégia queé, ela própria, intuitiva eindiciária, com grande val orização da experiência; mas ainda assim, essa estratégia se rende a um corpo de literatura queé, como já visto anteriormente, quase totalmente quantitativista ${ }^{5}$.

A articulação entre a perspectiva epistemológica de quesó aquilo queémensurável egeneralizado é verdadeiramente "científico" e a estratégia de legitimação da biomedicina frente à sociedade pela sua "cientificidade" são o ponto de emergência da co-produção de duas tendências que se reforçam mutuamente. Por um lado, a produção textual na qual o que é quantificável constitui a quase totalidade do que é publicado; por outro, uma prática profissional em cujo interior as técnicas direcionadas à singularidade e à subjetividade dos pacientes é desvalorizada e relegada a segundo plano, ao menos no plano do saber, a começar pelo ensino. Como compreender esta divergência? Este texto pretende apontar para uma possibilidade de resposta a esta questão, bem como apresentar dois exemplos de estudos sobre a própria medicina onde o uso de técnicas qualitativas foi fundamental para por em relevância os aspectos singulares e subjetivos usualmente imperceptíveis pela quantificação. Preliminarmente, contudo, e atendendo ao chamado dos autores citados no início deste texto, devo explicitar o referencial teórico que o embasa.

A referência teórica central destetexto éa epistemologia comparativa de Ludwik Fleck ${ }^{6,7}$. As próximas linhas apresentarão um esboço breve de seus desdobramentos teóricos; a atualidade e importância de Fleck são comentadas, entre outros, por Ian Hacking e Thomas Kuhn $n^{9,10}$.

Dois conceitos são centrais em Fleck: o coletivo de pensamento (Denkkollektiv) e ao estilo de pensamento (Denkstil). 0 primeiro é definido como [...] uma comunidade de pessoas intercambiando idéias mutuamente ou mantendo interação intelectual; também veremos por implicação que esta também provê 0 "suporte" especial para 0 desenvolvimento histórico de qualquer campo do pensamento, bem como do nível de cultura e conhecimento dados ${ }^{6}$ e o segundo como [...] uma 
constrição definida do pensamento, eatémais; [...] a totalidade da preparação ou disponibilidade intelectuais para uma forma particular de ver e agir ao invés de qualquer outra ${ }^{6}$. Note-se que 0 estilo de pensamento não é uma característica opcional que pode ser voluntariamente adotada, mas antes uma imposição feita pelo processo de socialização representado pela inclusão em um coletivo de pensamento.

Fleck distingue duas áreas de importância no interior deum coletivo depensamento na ciência moderna ${ }^{6}$, uma compreendendo os experts que efetivamente produzem conhecimento, por ele chamada de círculo esotérico (ele ainda detalha mais esta região, descrevendo o círculo mais interno de experts especializados e o círculo externo de experts generalistas), e o outra constituída pelos "leigos educados", o círculo exotérico. Esta topografia permite a distinção entre formas diferentes de comunicação ${ }^{6}$; a ciência dos experts é caracterizada pelo periódico técnico/científico e pelo livro de referência, o primeiro representando o diálogo intenso, fragmentado, pessoal e crítico dentro de um campo dado do conhecimento, e o segundo, a organização sinóptica deste ${ }^{6}$; o círculo exotérico éalimentado pelos periódicos de ciência popular ou de divulgação, que são uma "exposição artisticamenteatraente, vívida elegível [...] com uma atribuição de valores apodíctica para simplesmente aceitar ou rejeitar um dado ponto devista ${ }^{6 "}$. Final mente, a introdução ao círculo esotérico - comparada por Fleck a um ritual de iniciação $0^{6}$ - é baseada num quarto tipo de meio textual científico, o manual básico ${ }^{6}$.

Estes elementos permitem a construção da geografia deum campo intelectual, descrevendo não apenas pessoas e lugares, mas as trocas que ocorrem entre eles. Note-se que eu não pretendo atribuir a estes objetos mais valor do que o de uma notação conveniente - transformar o modelo de Fleck num relato ontologicamente fundado seria ir contra a própria lógica de suas idéias.

As instituições médicas (incluindo a saúde pública, a assistência à saúde e as escolas médicas), o conhecimento e prática médicos são permeados por um estilo de pensamento específi$\mathrm{CO}^{11}$. Um complicador adicional é o fato dequea medicina, enquanto prática social, extrai sua legitimidade de sua "cientificidade", embora não seja ela própria uma ciência em sentido estrito, isto é, ela depende do conhecimento produzido por outras disciplinas. Sendo assim, uma primeira explicação para a menor valorização de técnicas qual itativas passa pela necessidade de se identificar ao modelo das ciências "duras" do campo biomédico, em particular das biociências de um modo geral (como por exemplo a biologia molecular) e a epidemiologia, ambas embasadas em extenso instrumental matemático.

Deste modo, torna-se inteligível a assimetria apontada no início deste texto; o próprio estilo de pensamento damedicinatendea valorizar um conjunto de técnicas que, num certo sentido, Ihe são externas, ou ao menos externas ao que estetem de mais específico, isto é, a metodologia clínica.

Como exemplo das questões levantadas até aqui, comentarei rapidamente dois estudos empíricos realizados em momentos diferentes, que tiveram como objeto algum aspecto do campo de atuação da biomedicina: o primeiro sobre a experiência da internação hospitalar ${ }^{12}$, o segundo sobre 0 atendimento ambulatorial ${ }^{13}$.

O primeiro estudo baseou-se na observação participante deestudantes de medicina treinados nessa metodologia, que acompanharam todo o período deinternação de dezenovemulheres, com duas a três visitas de trinta a quarenta minutos cada. 0 segundo utilizou também a observação participante, com os mesmos estudantes acompanhando consultas ambulatoriais num período de cerca de seis meses. 0 último estudo foi baseado num conjunto de entrevistas com informantes-chave, selecionados entre os professores mais respeitados (identificados por outro conjunto de entrevistas, com estudantes de medicina) de duas tradicionais faculdades de medicina do Rio de Janeiro.

Tomados em conjunto, estes estudos compõem um painel sobre vários espaços da atuação médica, dos valores e crenças que guiam a sua estratégia de aquisição de informações, ao atendimento prestado em diferentes espaços institucionais. Os dois estudos mostraram a solicitação intensa dealgum tipo delaço afetivo por parte dos pacientes, ea não-percepção sistemática dessa busca por parte dos médicos. Eles apontaram ainda para um gap comunicacional na interação médico/paciente, que por vezes pareciam manter um verdadeiro diálogo de surdos, onde ao invés de interação observava-se o estabelecimento de dois discursos paralelos. 0 segundo estudo apontou para uma relação bastante flexível entre 0 acervo do conhecimento médico disponível esua aplicação, mostrando que a prática biomédica não ésimples decorrência lógica de um conhecimento transformado em ação. Finalmente, os dois estudos apontaram para a importância do conhecimento formal da biomedicina como aspecto de valorização profissional e mesmo de legitimação social da prática médica, o que auxilia 
a explicar tanto as dificuldades na interação com pacientes naquilo queescapa a esse modelo ( tudo que diz respeito à subjetividade, por exemplo) quanto a valorização dos aspectos mais "duros" do modelo mesmo quando esse não auxilia ou até entra em conflito com as situações encontradas na prática.

Estas inferências, formuladas com base em processo interpretativo orientado pela epistemologiafleckiana, dificilmente seriam alcançadas de outra forma. 0 conjunto destes estudos permitiu explicitar um estilo de pensamento pouco reflexivo com relação às suas próprias bases, que valoriza excessivamente determinados processos de produção de conhecimento sem que estes sejam propriamente apreendidos criticamente, contradizendo em parte as observações de $M$ aykrut e $M$ orehouse ${ }^{2}$ relatadas no início deste texto. Se de fato as concepções filosóficas subjacentes às técnicas qualitativas são pouco conhecidas, isto não autoriza supor por outro lado queinversamente os pressupostos subjacentes às técnicas quantitativas sejam melhor compreendidos. Em particular, estes estudos colocaram em questão a idéia de que a prática médica seja knowledge driven, ou seja, que o conhecimento técnico determine de forma unívoca as ações dos médicos.

Tendo em vista o gap descrito acima, a realização de mais estudos baseados em metodologias qualitativas, bem como a publicação deles resultantes, poderá, em princípio, permitir a apreensão mais am pla das ricas inter-relações que constituem a atenção à saúde. Por sua vez, uma maior visibilidade dos aspectos singulares e subjetivos dos saberes e práticas da saúde poderá, talvez, trazêlos da relativa penumbra que ora ocupam. Fica portanto o desafio a pesquisadores, profissionais e, talvez, sobretudo, a editores de publicações científicas, de promover uma maior produção e divulgação de estudos baseados em técnicas qualitativas sobre a biomedicina.

\section{Referências}

1. Taylor C. Interpretation and the sciences of man. In: Klemke ED, Hollinger R, Rudge DW, editors. Introductory readings in the philosophy of science. Amherst: Prometheus Books; 1988.

2. Maykrut $\mathbf{P}, \mathbf{M}$ orehouse $\mathrm{R}$. Beginning qualitative research: a philosophical and practical guide. London: The Falmer Press; 1994.

3. Foucault M. O nascimento da clínica. Rio de Janeiro: Forense U niversitária; 1980.

4. Ginzburg C. Sinais: raízes de um paradigma indiciário. In: Ginzburg C. M itos, emblemas, sinais. São Paulo: Cia. das Letras; 1989.

5. Camargo Jr KR. Sobre palheiros, agulhas, doutores e o conhecimento médico: o estilo de pensamento dos clínicos. Cad Saúde Pública 2003;19(4):1163-1174.

6. Fleck L. Genesis and development of a scientific fact. Chicago: University of Chicago Press; 1979.

7. Cohen RS, Schnelle T, editors. Cognition and fact materials on Ludwik Fleck. Dordrecht: D. Reidel; 1986.

8. Hacking I. The social construction of what? Cambridge, M assachussets: H arvard University Press; 1999.

9. Kuhn TS. Foreword. In: Fleck L. Genesis and development of a scientific fact. Chicago: U niversity of Chicago Press; 1979.
10. Kuhn TS. The structure of scientific revolutions. $3^{\text {rd }}$ ed. Chicago: University of Chicago Press; 1996.

11. Fleck L. Some specific features of the medical way of thinking. In: Cohen RS, Schnelle T, editors. Cognition and fact - materials on Ludwik Fleck. Dordrecht: D. Reidel; 1986.

12. Camargo Jr KR, Lamas CC, Lins JAS, Bueno APS, Guimarães DP, Goffredo Filho GS. Um estudo sobre a internação hospitalar. Psicossomática 1988; $1(6): 20-27$.

13. Camargo Jr KR, Coeli CM. Theory in practice: why good medicine and scientific medicine are not necessarily the same thing. Advances In Health Sciences Education, 2006; 11(1):77-89.

Artigo apresentado em 07/08/2006

Aprovado em 27/06/2007 